\title{
Erodibility of aquaculture waste from different bottom substrates
}

\author{
B. A. Law $^{1,2, *}$, P. S. Hill ${ }^{2}$, T. G. Milligan ${ }^{1}$, V. Zions ${ }^{1}$ \\ ${ }^{1}$ Fisheries and Oceans Canada, Bedford Institute of Oceanography, Dartmouth, Nova Scotia B2Y 4A2, Canada \\ ${ }^{2}$ Department of Oceanography, Dalhousie University, Halifax, Nova Scotia, B3H 4J1, Canada
}

\begin{abstract}
A laboratory study was carried out to examine the effect of bed sediment texture on the erodibility of salmon aquaculture waste fecal material and salmon feed pellets. Erodibility measurements of this material were made using a Gust microcosm erosion chamber and artificially composed substrates of mud, sand, sand and gravel, sand and cobble, and cobble. Results show that cumulative mass eroded (CME) and erodibility constant $(M)$ can vary by up to an order of magnitude depending on substrate composition, with a mud substrate having higher CME and $M$ values than those of substrates composed of sand, gravel and cobble. Findings from this study suggest that bottom sediment texture plays a major role in aquaculture waste resuspension and subsequent transport and that predictive models of the transport of aquaculture waste should include the erosion dynamics of bottom texture.
\end{abstract}

KEY WORDS: Aquaculture $\cdot$ Erodibility $\cdot$ Waste transport $\cdot$ Bottom substrate

\section{INTRODUCTION}

With the expansion of the aquaculture industry, concerns have been raised over the fate of aquaculture waste material-primarily feed pellets and fecal matter-from salmon farming. Models that predict the transport and fate of particles in the coastal ocean are required by habitat managers, fisheries and aquaculture managers, and other government regulators, to understand marine water quality, contaminant transport, coastal erosion, and the cumulative effects from anthropogenic influences. Models presently being used for finfish aquaculture do not predict waste transport accurately because there is a lack of data with which to parameterize the cohesive nature and transport properties of fecal material, waste pellets, and their interaction with particulate matter in suspension and on the seabed.

Research related to particulate aquaculture waste has dealt primarily with deposition immediately under or adjacent to salmon net pens. Modelling and field studies have focused on near-field effects from

\footnotetext{
${ }^{*}$ Corresponding author: brent.law@mar.dfo-mpo.gc.ca
}

organic enrichment, while the far field has received far less attention. The near field is considered to be the area within a few hundred meters of farming operations, while the far field can extend kilometers away. Models to predict the depositional footprint from salmon and other finfish farms using the settling characteristics of waste solids have become increasingly accurate (Panchang et al. 1997, Cromey et al. 2002a,b, Chamberlain \& Stucchi 2007). Models that predict the subsequent resuspension and transport of waste material, however, are lacking (Chamberlain \& Stucchi 2007, Droppo et al. 2007, Reid et al. 2009). Development of coupled hydrodynamic-sediment transport models that can address the far field will require parameterization of the factors responsible for influencing the erosion of aquaculture waste material. Measurements of the erodibility of waste particles associated with aquaculture are lacking, which limits understanding of potential far-field transport and possible environmental impacts.

Wave and current stress exerted on the seabed provide the work necessary to erode particles from

() The authors 2016. Open Access under Creative Commons by Attribution Licence. Use, distribution and reproduction are unrestricted. Authors and original publication must be credited. 
the seabed, whereas particle size and mass, bed roughness, cohesion, porosity, consolidation, and biological activity control the erosion resistance of the seabed (Amos et al. 1992, 1997, Maa et al. 1998, Sanford \& Maa 2001, Wiberg et al. 2013). Overall understanding of cohesive sediment resuspension is incomplete because it is governed by not only hydrodynamic forces and the force of gravity, but also by cohesion, which depends on biological and electrochemical variables (Black et al. 2002, Droppo et al. 2007). The highly organic nature of aquaculture wastes endows them with cohesive properties, which could significantly impact their erodibility.

Boundary shear stress is defined as the force per unit of area that flowing water exerts on the seabed. Particles at the surface of the seabed move when the downstream (i.e. fluid drag) and upward (i.e. fluid lift) forces overcome the forces keeping a particle in contact with the bed (Wiberg \& Smith 1987). The stress on the bed required to induce motion is the critical erosion shear stress, which is denoted $\tau_{\text {crit }}$ (Einstein 1950, Partheniades 1962, Amos et al. 1992, Tolhurst et al. 1999). There have been many investigations of the erosion of non-cohesive (e.g. Shields 1936, Soulsby 1997) and cohesive seabeds (Winterwerp 1989, Amos et al. 1992, 1997). In the broadest terms, non-cohesive sediments have mean grain sizes $>63 \mu \mathrm{m}$, and cohesive sediments or 'muds' are dominated by fine-grained particles that are $<63 \mu \mathrm{m}$. More recently, attention has also been given to erosion of sand-mud mixtures that show complex behaviours strongly influenced by the fraction of mud in the mixture (van Ledden et al. 2004, Law et al. 2008, Wiberg et al. 2013). Little research has focused on the erosion of aquaculture waste solids.

The model DEPOMOD was developed to predict solids waste accumulation on the seabed associated with fish-farming activity (Cromey et al. 2002a). While primarily addressing the initial deposition of waste, DEPOMOD also employs a simple resuspension module to redistribute waste particles according to near-bed currents. The resuspension module uses the erosion formula:

$$
M_{\mathrm{e}}=M\left[\left(\tau_{\mathrm{bot}} / \tau_{\mathrm{crit}}\right)-1\right]
$$

where $M_{\mathrm{e}}$ is the erosion rate $\left(\mathrm{kg} \mathrm{m}^{-2} \mathrm{~s}^{-1}\right)$, $\tau_{\mathrm{bot}}(\mathrm{Pa})$ is the applied bottom stress, $\tau_{\text {crit }}(\mathrm{Pa})$ is the critical stress for erosion, and $M$ is an erodibility constant $\left(\mathrm{kg} \mathrm{m}^{-2}\right.$ $\mathrm{s}^{-1}$ ). In the module the values of $M$ and $\tau_{\text {crit }}$ are hardcoded to be $7.0 \times 10^{-7} \mathrm{~kg} \mathrm{~m}^{-2} \mathrm{~s}^{-1}$ and $0.0179 \mathrm{~Pa}$ (9.5 $\mathrm{cm} \mathrm{s}^{-1}$ flow speed), respectively. DEPOMOD does not consider variation in bottom substrate and its effect on erodibility.
To examine the effect of bottom type on erosion, aquaculture wastes were placed on top of sediment cores that contained different substrates. The cores were eroded in the laboratory with a Gust microcosm erosion chamber. The bottom substrates used were representative of a range of seabed types found under aquaculture sites. The methods used were the same as those used in the field for making direct measurements of sediment erodibility. Results are presented in terms of the erodibility parameter, $M$, and the critical erosion stress (i.e. $\tau_{\text {crit }}$ ) required to mobilize waste particles.

\section{MATERIALS AND METHODS}

\section{Overview}

Cores representing different bottom types were made in $10.8 \mathrm{~cm}$ core barrels. Five different bottom types were used: mud, sand, sand and gravel, sand and cobble, and cobble (Fig. S1 in the Supplement at www.int-res.com/articles/suppl/q008p575_supp.pdf). In each core, seawater was added to a depth of $10 \mathrm{~cm}$ above the sediment surface. For each substrate type, waste material from salmon was allowed to settle onto the surface of the core. The salmon waste was collected from tanks at the Coldbrook (Nova Scotia, Canada) fish hatchery. Salmon fecal material comprised intact and disintegrated fecal material. It was added gently to the tops of the artificial cores $2 \mathrm{~h}$ before erosion studies commenced to allow sufficient time for the material to settle. The mass of fecal material added to each erosion experiment was determined by gravimetric analysis. The erodibility of salmon feed pellets was examined by depositing pellets on the different surfaces. Each core was then fitted with a Gust erosion chamber to determine the erosion shear stress and mass eroded.

\section{Gust chamber}

The Gust chamber is an erosion simulator that comprises polycarbonate housing with a rotating disk, a removable lid, and water input and output connections. It fits directly on top of a core tube. By controlling both the rotation rate of the disk and the rate at which water is pumped through the device, a uniform shear stress is applied across the sediment surface. Shear stresses applied to cores were 0.01, $0.08,0.16,0.24,0.32,0.40,0.48$, and 0.60 Pa. Shear stress at each level was applied until an attached 
turbidity meter recorded values that corresponded to background concentrations, which was $30 \mathrm{~min}$ for $0.01 \mathrm{~Pa}$ stress, and $20 \mathrm{~min}$ for each successive shear stress. Background water, which was seawater filtered at $0.45 \mu \mathrm{m}$ to remove particles, was pumped into the chamber and withdrawn from an outlet in the lid to maintain the desired shear stress. The water exiting the chamber, which contained eroded particles, was pumped from the chamber through the turbidity meter, collected in a 21 flask and filtered for suspended particulate matter (SPM). The turbidity meter and SPM data were used to calculate cumulative mass eroded and $\tau_{\text {crit }}$ for each core. For a complete description of the Gust chamber, its function, and calibration, see Gust \& Müller (1997), Tolhurst et al. (2000) and Stevens et al. (2007).

\section{Substrates}

The bottom substrates (Fig. S1) were chosen to be representative of the seabed types in which salmon aquaculture is active in Canada or where new sites may be developed. The mud core was formed from mud collected in St. Peters Bay, Prince Edward Island, that had a median diameter (d50) of $10 \mu \mathrm{m}$. The mud core was pre-eroded without waste in order to obtain a smooth, consolidated mud bed which was used in the erosion studies. This treatment prevented mixing of resuspended substrate mud with waste particles. The sand used in the experiment was from Lawrencetown Beach, Nova Scotia and had a d50 of $\sim 250 \mu \mathrm{m}$. The gravel was a quarry grade, and $65 \%$ of the mass had diameters between 2 and $2.5 \mathrm{~mm}$ and $85 \%$ of the mass had diameters $>1.5 \mathrm{~mm}$. The cobble classification had only a small percentage of actual cobble (i.e. $>64 \mathrm{~mm}$ ), most of the sediment in this class was actually larger gravel between 20 and $50 \mathrm{~mm}$, which came from Lawrencetown Beach, but the classification of cobble was used to distinguish it from smaller gravel used in these experiments. All classifications of grain size are based on the Wentworth scale.

For each substrate type and waste material, the experiments were performed 6 times. The salmon fecal material erosion studies were performed in triplicate with waste material collected in the summer and again in triplicate with waste material collected in the winter. The seasonal inter-comparison was conducted to determine if there were seasonal differences in waste material resuspension due to differences in waste material associated with decreased feeding and metabolic processes in winter. There were no discernable differences in the resuspension dynamics in terms of erosion rate or cumulative mass eroded, therefore winter and summer data sets were combined.

Experiments with salmon feed pellets were carried out in the same manner using mud, sand, and cobble substrates. Feed pellets that were $5 \mathrm{~mm}$ in diameter and $9 \mathrm{~mm}$ in diameter were used to represent a range of pellets fed to small and large salmon, respectively, during the grow out process. Critical stress for motion was based on when at least one of the pellets moved, and rolling and saltating classifications were based on when half of the pellets were in that specific motion. In these experiments, rolling means the movement of pellets along the core top while saltating means the bouncing of pellets. The horizontal transport speeds $\left(\mathrm{mm} \mathrm{s}^{-1}\right)$ listed herein are based on the majority of pellets moving around the core at an equal spacing from the core wall. Wall effects are not accounted for and only general trends are reported.

\section{Erosion calculations}

The mass eroded per unit area at each shear stress step was calculated by multiplying the SPM for each shear stress step by the total volume of water collected for each stress step, and then dividing by the area of the eroded surface $\left(0.0092 \mathrm{~m}^{2}\right)$. The cumulative mass eroded (CME, $\mathrm{kg} \mathrm{m}^{-2}$ ) is the sum of the mass eroded for each shear stress step. The erodibility parameter $(M)$ was determined based on Eq. (1) and is an average value calculated up to and including a bottom shear stress of $0.60 \mathrm{~Pa}$. An average erodibility parameter $M$ is presented as a means to compare the results of this study with the parameters used in DEPOMOD.

\section{RESULTS}

$\tau_{\text {crit }}$ (the stress at which waste material was initially resuspended from the surface) was determined to be $0.01 \mathrm{~Pa}$ for all bottom types (Fig. 1, Table 1). The erodibility of salmon aquaculture waste solids from different bottom substrates resembled that of a Type I (i.e. depth-limited) erosion (Amos et al. 1992; our Fig. 1). A plot of turbidity, which is a proxy for suspended mass concentration, with time for increasing bottom shear stresses in the Gust chamber shows an erosion pattern in which once the new shear stress is applied to the bottom substrate, the concentration of waste solids rapidly increases as they are eroded 


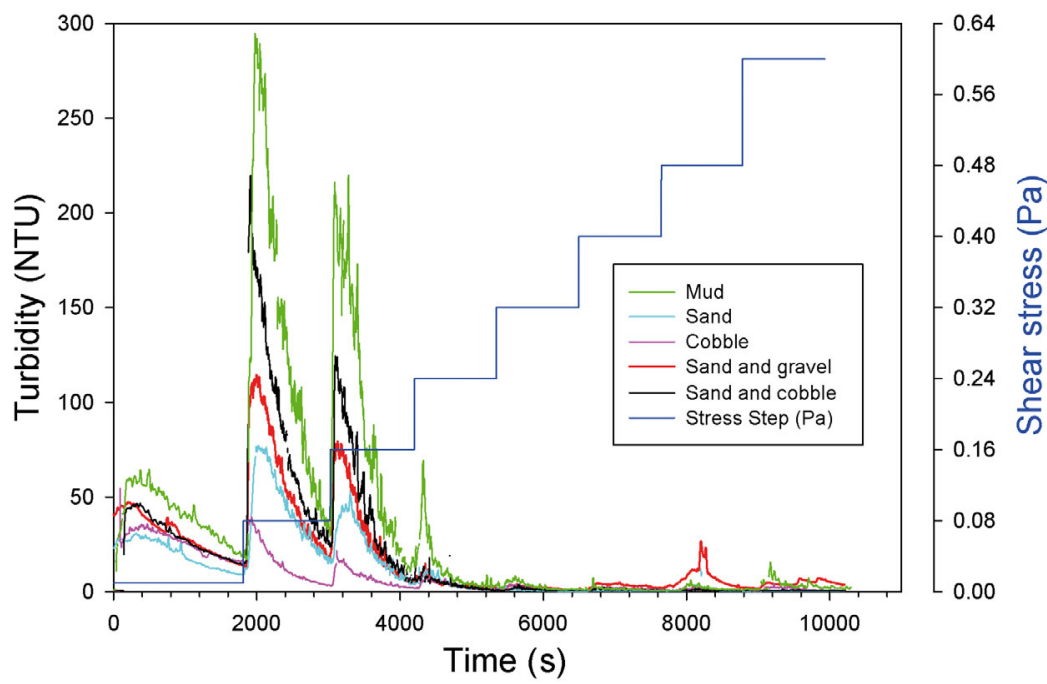

Fig. 1. Turbidity versus time plot from the Gust erosion studies of salmon aquaculture waste material on different bottom substrates (mud, sand, cobble, sand and gravel, sand and cobble). The plot was generated from Campbell turbidity sensors attached to the Gust erosion chamber. Shear stress was increased in discrete steps to a maximum of $0.60 \mathrm{~Pa}$

from the bed and then decreases exponentially as resuspended wastes exit the well-mixed chamber via the exhalant flow (Fig. 1). Visual observation of waste solids eroded from the different bottom substrates suggests that aggregated waste particles dominate at lower shear stress (i.e. $0.01 \mathrm{~Pa}$ and $0.08 \mathrm{~Pa}$; Fig. S2 in the Supplement).

Comparison of 5 different bottom substrates indicates that more wastes were eroded from muddy substrates than from sandy and gravel substrates (Fig. 1). The erosion experiments also showed that little to no erosion of waste solids or bottom substrate occurred $>0.32 \mathrm{~Pa}$, which was evidenced by low turbidity (Fig. 1). In all but the erosion experiments conducted on a muddy seabed, there was evidence that some of the waste solids remained even after

Table 1. Erodibility parameter $(M)$ values for erosion of salmon fecal waste material on the 5 different bottom substrates in the Gust erosion chamber experiments $(\mathrm{n}=6$ per substrate). Critical shear stress $\left(\tau_{\text {crit }}\right)=0.01 \mathrm{~Pa}$ in all experiments; with $\tau_{\text {crit }}$ being the shear stress required for incipient motion of fecal waste material

\begin{tabular}{|lcc|}
\hline Substrate & \multicolumn{2}{c|}{$M\left(\mathrm{~kg} \mathrm{~m}^{-2} \mathrm{~s}^{-1}\right)$} \\
& Mean & $\mathrm{SD}$ \\
\hline Mud & $1.3 \times 10^{-6}$ & $4.9 \times 10^{-7}$ \\
Sand & $3.5 \times 10^{-7}$ & $1.5 \times 10^{-7}$ \\
Cobble & $4.5 \times 10^{-8}$ & $1.8 \times 10^{-8}$ \\
Sand \& gravel & $6.0 \times 10^{-7}$ & $1.9 \times 10^{-7}$ \\
Sand \& cobble & $5.8 \times 10^{-7}$ & $2.7 \times 10^{-7}$ \\
\hline
\end{tabular}

the complete erosion experiments, which were conducted up to and including $0.60 \mathrm{~Pa}$ (Fig. 2). On average $>97 \%$ of salmon waste material added to the mud substrate was eroded, while $<25 \%$ of the material added to the cobble substrate was removed (Fig. 2). The substrates composed of sand averaged $\sim 65 \%$ removal from the bed (Fig. 2). These percentages were determined by dividing the CME by the total amount of waste material added to each core.

Average $( \pm \mathrm{SD}) \mathrm{CME}$ up to and including the $0.60 \mathrm{~Pa}$ stress step for the salmon waste experiments was $0.030 \pm$ $0.013 \mathrm{~kg} \mathrm{~m}^{-2}$ for the sandy bottom substrate, $0.116 \pm 0.041 \mathrm{~kg} \mathrm{~m}^{-2}$ for the muddy seabed, $0.055 \pm 0.017 \mathrm{~kg} \mathrm{~m}^{-2}$ for the seabed composed of sand and gravel, $0.049 \pm 0.023 \mathrm{~kg} \mathrm{~m}^{-2}$ for the sand and cobble seabed, and $0.005 \pm 0.002 \mathrm{~kg}$ $\mathrm{m}^{-2}$ for the cobble (mostly larger gravel) seabed (Fig. 3). The CME from the cobble substrate was only $5 \%$ as large as the CME from the mud substrate. The sand substrate yielded CME values that were approximately 4 times less than the mud substrate, while sand and gravel and sand and cobble had CME values around half of that of the mud substrate.

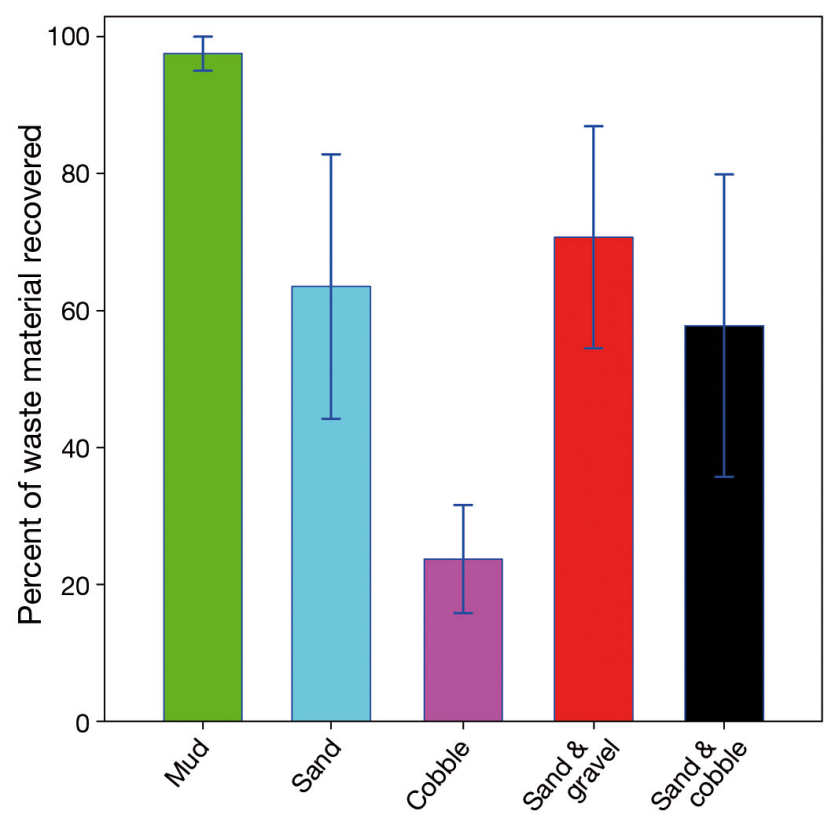

Fig. 2. Percent of salmon aquaculture waste material (mean $\pm \mathrm{SD})$ recovered from the erosion experiments $(n=6) \mathrm{com}-$ pleted on each bottom substrate (mud, sand, cobble, sand and gravel, sand and cobble) 


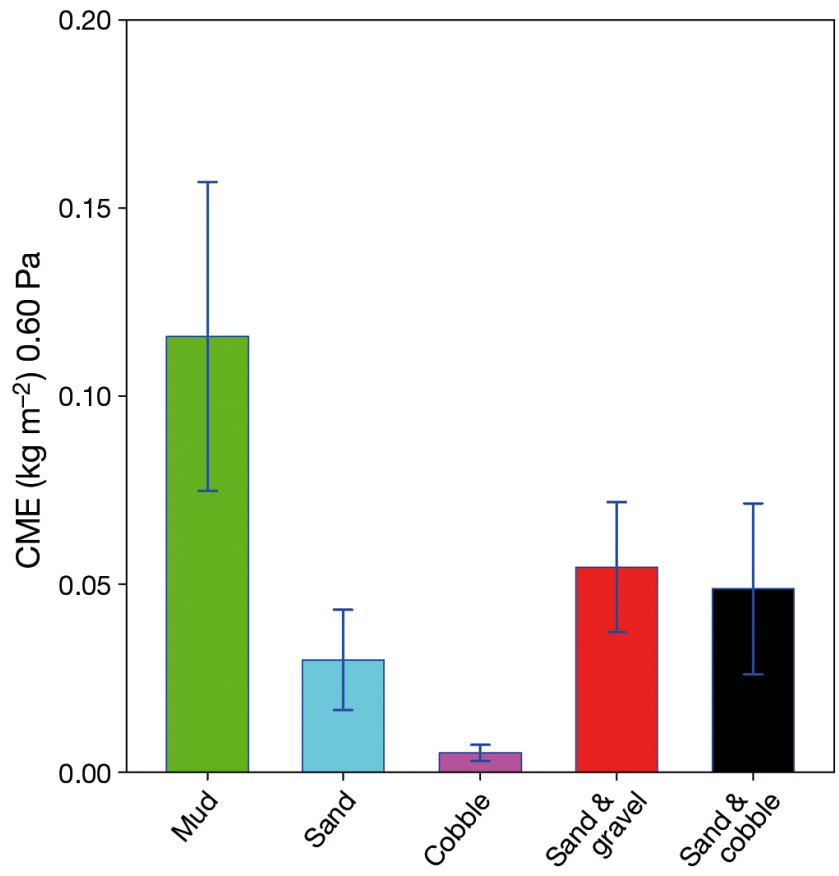

Fig. 3. Cumulative mass eroded $\left(\mathrm{CME}_{\text {; }}\right.$ mean $\left.\pm \mathrm{SD}_{i} \mathrm{~kg} \mathrm{~m}^{-2}\right)$ up to and including the $0.60 \mathrm{~Pa}$ shear stress step for the erosion experiments ( $\mathrm{n}=6$ per substrate type) using salmon fecal waste material. Results are normalized to \% recovery of waste material from the 5 different bottom substrates (mud, sand, cobble, sand and gravel, sand and cobble)

$\tau_{\text {crit }}$ for the motion of feed pellets varied depending on bottom type and pellet size (Table 2). For $5 \mathrm{~mm}$ feed pellets, $\tau_{\text {crit }}$ was $0.03,0.08$ and $0.20 \mathrm{~Pa}$ for mud, sand, and cobble, respectively. For $9 \mathrm{~mm}$ feed pellets, $\tau_{\text {crit }}$ was $0.04,0.08$, and 0.28 Pa for the mud, sand and cobble substrates, respectively. Horizontal transport speeds on the different substrates and at different stresses were calculated based on the number of revolutions the feed pellets made in the Gust chamber over a given period of time divided by the outside circumference of the tube (Table 2). Generally, transport speeds ranged from 10 to $75 \mathrm{~mm} \mathrm{~s}^{-1}$ for feed pellets on the mud and sand substrates but were negligible on the cobble substrate. Pellets in the cobble moved slightly from one crevice to another with time but later became lodged in the substrate.

\section{DISCUSSION}

\section{Critical erosion shear stress $\left(\tau_{\text {crit }}\right)$}

$\tau_{\text {crit }}$ was determined to be 0.01 Pa for salmon waste fecal material (Fig. 1, Table 1). This value is similar to that previously proposed by Cromey et al. (2002a) who used synthetic tracer beads to simulate salmon waste and reported a $\tau_{\text {crit }}$ of $0.0179 \mathrm{~Pa}$, which is most commonly referenced as a 'hard-coded' value for resuspension in DEPOMOD. This stress corresponds to a flow velocity of $\sim 9.5 \mathrm{~cm} \mathrm{~s}^{-1}$. The numbers reported in this study and that of Cromey et al. $(2002 \mathrm{a}, \mathrm{b})$ are similar to other published values for floc erosion (Amos et al. 1997, Thomsen \& Gust 2000, Law et al. 2008, Milligan \& Law 2013). More consolidated cohesive seabeds have higher $\tau_{\text {crit }}$ values, ranging from 0.03 to $0.08 \mathrm{~Pa}$ (Sanford \& Maa 2001, Stevens et al. 2007, Dickhudt et al. 2010, Wiberg et al. 2013). In the present study, material first eroded at $0.01 \mathrm{~Pa}$, but the bulk of waste material mass resuspended at the subsequent erosion stress step of $0.08 \mathrm{~Pa}$ (Fig. 1). This behaviour is similar to erosion experiments documented in field studies (Stevens et al. 2007, Dickhudt et al. 2010, Wiberg et al. 2013).

$\tau_{\text {crit }}$ for feed pellets for the cobble bed was significantly larger than that for the sand and mud seabeds. This result is caused by the wedging of pellets in cracks and crevices in rocks, where they are sheltered from fluid drag and lift (Table 2). The critical

Table 2. Transport paramenters of salmon feed pellets (5.0 and $9.0 \mathrm{~mm}$ diameter) on each substrate type used in the erodibility study. $\tau_{\text {crit }}$ is the shear stress required for incipient motion of feed pellets

\begin{tabular}{|c|c|c|c|c|c|}
\hline Substrate & $\tau_{\text {crit }}(\mathrm{Pa})$ & $\begin{array}{r}\text { Horizonta } \\
\text { at differ } \\
0.08-0.16 \mathrm{~Pa}\end{array}$ & $\begin{array}{l}\text { transport }(\mathrm{mn} \\
\text { nt shear stres } \\
0.16-0.24 \mathrm{~Pa}\end{array}$ & $\begin{array}{l}\left.\mathrm{s}^{-1}\right) \\
\mathrm{es} \\
>24 \mathrm{~Pa}\end{array}$ & Comments \\
\hline $\begin{array}{l}\text { Mud } \\
\text { (consolidated) }\end{array}$ & $\begin{array}{l}5.0 \mathrm{~mm}: 0.03 \\
9.0 \mathrm{~mm}: 0.04\end{array}$ & $\sim 10$ & $\sim 20-30$ & $\sim 60-75$ & $\begin{array}{l}\text { Rolling at } 0.08 \mathrm{~Pa} \text {, saltating at } 0.24 \mathrm{~Pa} \text {; breakup } \\
\text { begins at } 0.16 \mathrm{~Pa}\end{array}$ \\
\hline Sand & 0.08 & $\sim 10$ & $\sim 20-30$ & $\sim 75$ & $\begin{array}{l}\text { Rolling at } 0.16-0.24 \mathrm{~Pa} \text {, some pellets bury in sand } \\
\text { at } 0.24-0.32 \mathrm{~Pa} \text {, at } 0.48-0.60 \mathrm{~Pa} \text { pellets unbury from } \\
\text { sand and saltate vigorously and start to break apart; } \\
\text { breakup begins at } 0.16 \mathrm{~Pa}\end{array}$ \\
\hline Cobble & $\begin{array}{l}5.0 \mathrm{~mm}: 0.2 \\
9.0 \mathrm{~mm}: 0.28\end{array}$ & 0 & 0 & 0 & Trapped in stress refuge \\
\hline
\end{tabular}


stress values obtained in this study for motion on sandy and muddy substrates were similar to those reported for rolling and saltating by Sutherland et al. (2006), which corresponded to flow velocities of $16-20 \mathrm{~cm} \mathrm{~s}^{-1}$ and $32-40 \mathrm{~cm} \mathrm{~s}^{-1}$, respectively. Feed pellet breakup occurred at an applied stress of 0.16 $\mathrm{Pa}$, which corresponds to flow velocity for pellet breakup reported by Stewart \& Grant (2002). As shear stress increased $>0.24 \mathrm{~Pa}$, pellets swelled and began to saltate, and breakup became evident (Table 2).

\section{Substrate type}

The cumulative mass of salmon fecal material eroded from the mud bed was an order of magnitude greater than that eroded from the cobble bed (Table 1, Fig. 3). The 3 substrates composed primarily of sand behaved similarly, with CME falling between that of cobble and mud substrates (Figs. $3 \& 4$ ). The data from this study shown in Fig. 4 represents the CME for salmon waste material eroded as a function of increasing shear stress. Other studies of sediment

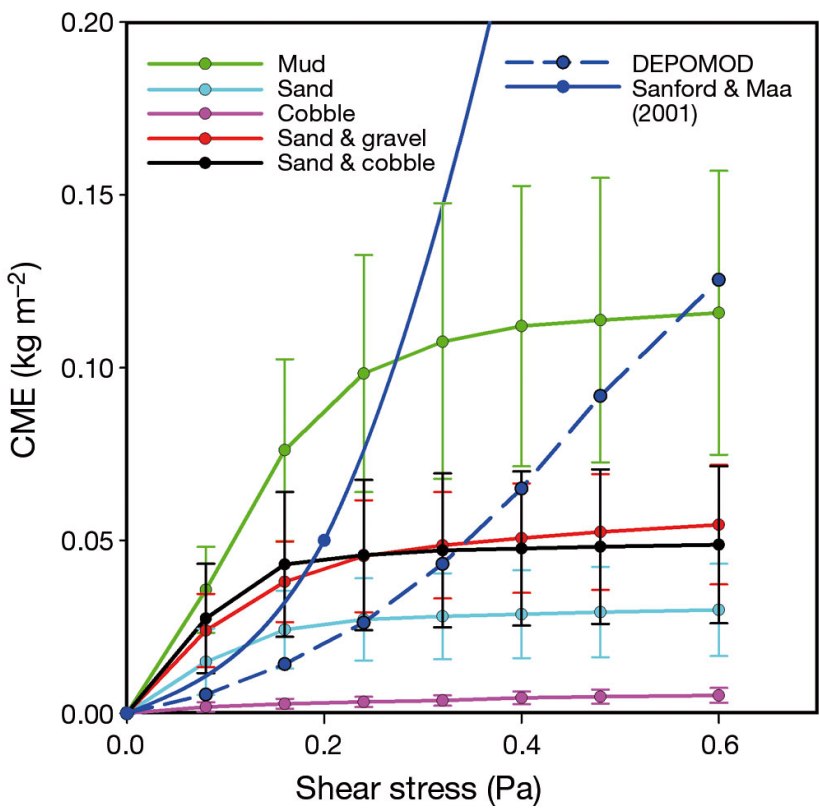

Fig. 4. Cumulative mass eroded $\left(\mathrm{CME}_{i}\right.$ mean $\left.\pm \mathrm{SD}\right)$ versus shear stress for the erosion experiments $(n=6$ per substrate type) of salmon fecal waste material on 5 different bottom substrates (mud, sand, cobble, sand and gravel, sand and cobble). In addition, a DEPOMOD prediction is included based on elapsed time and an erodibility parameter of $7.0 \times$ $10^{-7} \mathrm{~kg} \mathrm{~m}^{-2} \mathrm{~s}^{-1}$ (Cromey et al. 2002a,b). The dark blue line describes the actual data of Maa et al. (1998) which is described in detail in Sanford \& Maa (2001) and is included for comparison to this study transport have presented their results in this manner to look at changing erosion patterns with increasing shear (Sanford \& Maa 2001, Stevens et al. 2007, Dickhudt et al. 2010, Wiberg et al. 2013). The difference between this study and those mentioned above, which primarily looked at the erosion of cohesive seabeds, is that at $>0.32 \mathrm{~Pa}$ shear in this study, there was no longer the increase in the erosion of bottom material that was found in the other studies (Fig. 4). In natural bottom sediments, the erosion of the seabed increases with increasing shear stress (Amos et al. 1988, 1992, Maa et al. 1998). The lack of erosion at higher shear stresses in this study occurred because of the fixed amount of waste available for erosion (Wiberg et al. 1994, Law et al. 2008; our Fig. 4). In this study, almost the entire mass was eroded from a consolidated, flat, muddy seabed, whereas all coarser substrates acted to limit erosion.

One possible reason for the order of magnitude difference in erosion is that the cohesive nature of fecal material is variable and acts to limit erosion. Droppo et al. (2007) showed that aquaculture material can act to stabilize the seabed and increase erosion resistance. This seems less likely in this study as the fecal material added to cores was always from the same source and only sat on the tops of cores for $2 \mathrm{~h}$ prior to erosion studies, which likely provides insufficient time to stabilize the seabed. A second and more plausible explanation as to why a mud bed erodes more material (i.e. a higher erosion rate) seems to be due to the fact that fecal material becomes trapped between cobbles and is sheltered from erosion behind larger sand and gravel grains. In the sand and cobble and sand and gravel mixtures, much of the interstitial space is occupied by sand, but research has shown that particulate matter can be incorporated into sand beds as a result of bedform-induced interfacial flows (Heuttel et al 1996). The presence of gravel and cobble in these mixed substrates could also lead to the generation of turbulence that would enhance bottom stress, leading to greater erosion than from the sand bed alone.

\section{Erodibility parameter $(M)$}

In sediment transport models, in the absence of site-specific erosion measurements, $M$ governs the removal rate of material from the seabed when a bed stress greater than a critical stress is applied. In this study, $M$ represents an average erodibility parameter from 0.01 to $0.32 \mathrm{~Pa}$, the range over which aquaculture waste fecal material was removed from the 
seabed. The values of $M$ ranged over an order of magnitude from $\sim 1.3 \times 10^{-6} \mathrm{~kg} \mathrm{~m}^{-2} \mathrm{~s}^{-1}$ for the mud substrate to $4.5 \times 10^{-8} \mathrm{~kg} \mathrm{~m}^{-2} \mathrm{~s}^{-1}$ for the cobble substrate for the erosion of salmon waste material (Table 1). $M$ ranged from $2-8 \times 10^{-6} \mathrm{~kg} \mathrm{~m}^{-2} \mathrm{~s}^{-1}$ in the study of Sanford \& Maa (2001), which is a re-analysis of Maa et al. (1998), to $1.4 \times 10^{-6} \mathrm{~kg} \mathrm{~m}^{-2} \mathrm{~s}^{-1}$ in the study of Sanford et al. (1991), to $7.0 \times 10^{-7} \mathrm{~kg} \mathrm{~m}^{-2} \mathrm{~s}^{-1}$ in the DEPOMOD study of Cromey et al. (2002a). The erosion studies of Maa et al. (1998) and Sanford \& Maa (2001) were generally performed on muddy cohesive seabeds while the study of Cromey et al. (2002b) used synthetic tracer beds of similar size and settling velocity to represent aquaculture fecal material. A study by Harris et al. (1993) calculated $M$ to be $3.010^{-5} \mathrm{~kg} \mathrm{~m}^{-2} \mathrm{~s}^{-1}$ in an area with high critical shear velocity, indicative of a sandy environment. Broadly, $M$ varies over several orders of magnitude in a wide range of environments.

The values of $M$ from Sanford \& Maa (2001) would overestimate the erosion of waste material from this study (Fig. 4). At shear stresses $>0.32 \mathrm{~Pa}$, the cores in the present study were depleted of waste material or waste material was unavailable for erosion (i.e. trapped in the stress refuges or bed armoured) whereas in the Sanford \& Maa (2001) study, the seabed continued to be a source of resuspended mass as the bottom stress increased (Fig. 4). The value of $M$ used in the Cromey et al. $(2002 \mathrm{a}, \mathrm{b})$ study modeled the erodibility of waste in our study from that of a cobble seabed up to $0.24 \mathrm{~Pa}_{\text {, }}$ and then diverged with good estimation of erodibility for the seabed composed of sand in our study from 0.40 to $0.60 \mathrm{~Pa}$, the highest seabed stresses used in this study (Fig. 4). Using a single value of $M$ in DEPOMOD, although simplistic for modelling, becomes problematic, because as long as the bottom stress exceeds a single value of critical stress the model continues to erode waste material at a constant rate (i.e. $M$ ) with time and no depletion of the bed or waste material occurs.

\section{Modelling}

Recent sediment transport modelling efforts increase $\tau_{\text {crit }}$ with depth into the substrate to limit the amount of material that can be eroded until a new critical stress is exceeded (Stevens et al. 2007, Sanford 2008). The present study, using artificially created cores to examine aquaculture fecal material erodibility, showed similar erodibility characteristics, where an increase in $\tau_{\text {crit }}$ was required to continue to resuspend and remove waste fecal material from the bed (Figs. $1 \& 4$ ). When exceeding $0.32 \mathrm{~Pa}$, all the deposited material had either been eroded from the bed or was prevented from being eroded by becoming trapped in crevices, buried or armoured by heavier grains or waste (Fig. 4). The fecal waste material was given only a limited time to settle (i.e. $2 \mathrm{~h}$ ) and was in quiescent conditions with no stress applied during the settling process. It is therefore assumed that the removal of waste material from the substrates used in this study was a result of armouring by heavier sediment grains or waste and not due to consolidation or dewatering effects. The slowest settling material would have been the first removed from the erosion experiments followed by faster-settling material, predominantly larger fecal material assuming a similar density.

Sanford \& Maa (2001) proposed a linear formula for erosion with changing $\tau_{\text {crit }}$ with depth $(z)$, which takes the form of the equation:

$$
M_{\mathrm{e}}=M\left[\tau_{\text {bot }}-\tau_{\text {crit }}(\mathrm{z})\right]
$$

Using this linear formula the erosion results of this study could be modelled, but only up to $0.32 \mathrm{~Pa}$ of bottom stress if the correct erodibility parameter $M$ and $\tau_{\text {crit }}$ with depth were used. Eq. (1), as presently used in the resuspension module of DEPOMOD would not accurately predict the erosion of waste material from the seabed in our study even if a correct value of $M$ was used. The use of a constant erosion rate while $\tau_{\text {crit }}$ is exceeded results in an overestimate or underestimate of erosion depending on the flow velocity over the seabed. It is cautioned that the present study only represented a small number of erosion experiments with waste material $(n=6)$ and was not completed in situ, where hydrodynamics would play a major role in shaping bottom sediment texture and controlling the initial deposition of waste products. However, results from this experiment closely resemble those of Milligan \& Law (2013), which were for cores collected next to salmon aquaculture cages. This study does also not take into consideration the consolidation time required for waste fecal material to be incorporated into the seabed and how the interaction of waste with the seabed plays a role in the resuspension dynamics. Law et al. (2014) showed that small particles that were highly organic and possibly indicative of waste material could be incorporated in flocs once they were deposited on the seabed or incorporated into floc structures if components of waste material were broken down into very small constituents. If incorporation into floc-derived material occurred, then this waste material would be 


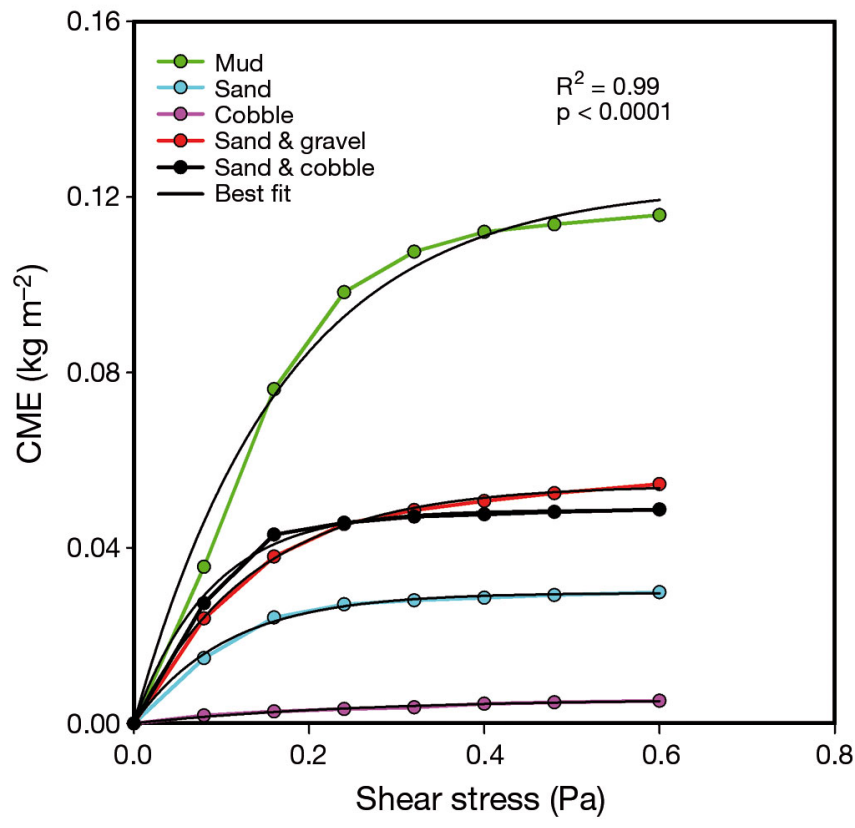

Fig. 5. Best fit plot of cumulative mass eroded (CME) versus shear stress for the erosion experiments $(n=6$ per substrate type) using salmon fecal waste material. The fits are based on the simple exponential rise to maximum equation (see Eq. 3)

easily transported even at the lowest stress used in this study.

Fig. 5 represents the best fit to the average CME curves based on the data collected in this study. A simple exponential rise to maximum equation following:

$$
\mathrm{CME}=a\left(1-\tau^{b}\right)
$$

explains the majority of the erosion data (i.e. $\mathrm{R}^{2}=$ 0.99, $\mathrm{p}<0.0001)$. The parameters $a$ and $b$ represent the maximum CME eroded for each bottom type and the rate of removing material from each bottom type, respectively (Table 3 ). The larger ' $b$ ' value indicates that it approaches the value ' $a$ ' faster. Muds approach

Table 3. Parameters for modelled fits (all $\mathrm{R}^{2}=0.99, \mathrm{p}<$ 0.0001 ) of cumulative mass eroded versus shear stress (see Eq. 3) for the 5 different bottom substrates of the erosion experiments

\begin{tabular}{|lcc|}
\hline Substrate & $a$ & $b$ \\
\hline Mud & 0.123 & 0.00290 \\
Sand & 0.03 & 0.000076 \\
Cobble & 0.006 & 0.02100 \\
Sand \& gravel & 0.054 & 0.00060 \\
Sand \& cobble & 0.049 & 0.000013 \\
\hline
\end{tabular}

' $a$ ' fast because the waste is eroded completely and has no spot to hide or way to become armoured by the bed. Cobble approaches 'a' fast because most of the material available for resupension gets driven into the bed (i.e. crevices) at low stress and only the easily eroded flocculated material gets eroded. Sands act between that of mud and cobble with active bed exchange driving some of the waste into the bed with about half of the material being resuspended and removed. It is possible Eq. (3) could be used in aquaculture waste transport models to simulate the erosion of waste from differing seabed types by using the appropriate values for $a$ and $b$ under conditions where supply from the bed is limited.

In addition to waste fecal material, it is necessary for waste feed pellets to be treated separately in aquaculture waste transport models. Presently, the resuspension component of DEPOMOD treats waste fecal material and feed pellets as a single entity with one erosion parameter (Cromey et al. 2002). Chamberlain \& Stucchi (2007) hypothesized that the seabed geochemistry as a result of organic loading at their study sites were affected by feed pellet deposition even though their model output suggested that all waste material would be transported out of their model domain when the resuspension component of DEPOMOD was turned on. Evidence from the present study, as well as the study of Sutherland et al. (2006), suggests that much higher shear stress values are required to transport feed pellets than the single number of $0.0179 \mathrm{~Pa}$ 'hard-coded' in the DEPOMOD model. In addition, thought should be given to the exposure of feed pellets to the marine environment. Stewart \& Grant (2002) showed in laboratory studies that most feed pellets break down and disintegrate in much smaller constituents within $\sim 30 \mathrm{~d}$ of being in the water.

At present the deposition of aquaculture waste material in DEPOMOD is governed by a settling velocity of $3.4 \mathrm{~mm} \mathrm{~s}^{-1}$ for fecal material and $100 \mathrm{~mm}$ $\mathrm{s}^{-1}$ for feed pellets. The resuspension of these materials is treated with 1 erosion parameter and 1 single value for $\tau_{\text {crit. }}$. If DEPOMOD or a newer updated version is to be used as the community aquaculture waste transport model, then provisions could be made to include multiple groups of material each with their own settling velocities and critical stress for erosion. The groups could also include their own transport parameters such as $M$ and would need to be related to the amount of input added to aquaculture sites. Future erosion work using experiments both in laboratory and in situ at aquaculture sites will help further refine waste transport parameters. 


\section{Implications}

Recent work on size sorting during the erosion of cores from the Gulf of Lions, France (Law et al. 2008) and in Seal Harbour, Nova Scotia, Canada (Milligan \& Law 2013) suggests that increases in clay (sediment particles $<4 \mu \mathrm{m}$ in diameter) changes resuspension dynamics. In sediments that contain $>7.5 \%$ clay, a wide range of sizes are eroded at reduced but equal rates. Sediments with a smaller clay fraction exhibit greater erodibility and size-selective sorting over the entire particle size range. Sediment with a small clay fraction can be winnowed of its fine fraction during erosion, but sediments with a larger clay fraction cannot. When muddy sands are eroded, the smallest sediment sizes are winnowed from the bed, essentially cleaning the sands. In contrast, when muds are eroded, size sorting is reduced substantially. In short, after deposition, sands are 'cleaned' by physical disturbance, but muds resist any further sorting. Even if muds are repeatedly resuspended and transported over great distances, they maintain their poorly sorted character and small mean grain size. Further research on bedform-induced interfacial flows have shown the ability of the flow to transfer suspended particles from the boundary layer and into surficial sediments which produce structural heterogeneity of the seabed (Huettel et al. 1996, Chen et al. 2010). It was evident in this research that coarse substrates such as cobble, sands, and gravel have the ability to retain aquaculture waste even at higher flow speeds. Implications may then exist in areas of open-cage aquaculture over coarse substrate that bed dynamics may change from one of non-cohesive to cohesive. Further research on this topic is warranted.

\section{CONCLUSIONS}

Bottom sediment substrate plays a role in the erodibility of aquaculture waste material. An order of magnitude difference exists in the cumulative mass eroded of waste fecal material and subsequently the erosion parameter $M$ between a mud and cobble seabed. A seabed composed of sand erodes between that of cobble and mud. Feed pellets experience large differences in $\tau_{\text {crit }}$ between the same seabed types. It is therefore critical that waste fecal material and feed pellets be treated as separate entities in aquaculture waste transport models. Future work should focus on the consolidation time of waste material and its incorporation into the seabed and subsequent re-working. Erosion studies should also take place at areas of active aquaculture sites with differing bottom types to validate the results seen in this laboratory study. Refining transport parameters and future model validation will help increase our predictive capacity of waste transport to the far field and help understand possible ecosystem response.

Acknowledgements. The authors thank the employees of the Fisheries and Oceans Canada Coldbrook fish hatchery and 4 anonymous reviewers for their comments and suggestions.

\section{LITERATURE CITED}

Amos CL, VanWagoner NA, Daborn GR (1988) The influence of subaerial exposure on the bulk properties of finegrained intertidal sediment from Minas Basin, Bay of Fundy. Estuar Coast Shelf Sci 27:1-13

Amos CL, Daborn GR, Christian HA, Atkinson A, Robertson A (1992) In situ erosion measurements on fine grained sediments from the Bay of Fundy. Mar Geol 108:175-196

Amos CL, Feeney F, Sutherland TF, Luternauer JL (1997) The stability of fine-grained sediments from the Fraser River Delta. Estuar Coast Shelf Sci 45:507-524

Black KS, Tolhurst TJ, Paterson DM, Hagerthy SE (2002) Working with natural cohesive sediments. J Hydraul Eng 128:2-8

Chamberlain J, Stucchi D (2007) Simulating the effects of parameter uncertainty on waste model predictions of marine finfish aquaculture. Aquaculture 272:296-311

Chen C, Packman AI, Zhang D, Gaillard JF (2010) A multiscale investigation of interfacial transport, pore fluid flow and fine particle deposition in a sediment bed. Water Resour Res 46:413-427

Cromey CJ, Thomas TD, Black KD (2002a) DEPOMODmodeling the deposition and biological effects of waste solids from marine cage farms. Aquaculture 214:211-239

> Cromey CJ, Nickell TD, Black KD, Provost PG, Griffiths CR (2002b) Validation of a fish farm waste resuspension model by use of a particulate tracer discharged from a point source in a coastal environment. Estuaries 25: 916-929

> Dickhudt PJ, Friedrichs CT, Sanford LP (2010) Mud matrix solids fraction and bed erodibility in the York River estuary, USA and other muddy environments. Cont Shelf Res 31(Suppl):S3-S13

Droppo I, Jaskot C, Nelson T, Milne J, Charlton M (2007) Aquaculture waste sediment stability: implications for waste migration. Water Air Soil Pollut 183:59-69

Einstein HA (1950) The bed-load function for sediment transportation in open channel flows. US Dept Agricult Tech Bull 1026

Gust G, Müller V (1997) Interfacial hydrodynamics and entrainment functions of currently used erosion devices. In: Burt N, Parker R, Watts J (eds) Cohesive sediments. Wiley, Chichester, p 149-174

Harris JR, Gorley RN, Bartlett CA 1993. ECoS Version 2a user manual. Marine Laboratory, Plymouth

> Huettel M, Ziebis W, Forster S (1996) Flow-induced uptake of particulate matter in permeable sediments. Limnol Oceanogr 41:309-322

Law BA, Hill PS, Milligan TG, Curran KJ, Wiberg PL, Wheatcroft RA (2008) Size sorting of fine-grained sediments 
during erosion: results from the western Gulf of Lions. Cont Shelf Res 28:1935-1946

Law BA, Hill PS, Maier I, Milligan TG, Page F (2014) Size, settling velocity and density of small suspended particles at an active salmon aquaculture site. Aquacult Environ Interact 6:29-42

Maa JPY, Sanford LP, Halka JP (1998) Sediment resuspension characteristics in Baltimore Harbour, Maryland. Mar Geol 146:137-145

Milligan TG, Law BA (2013) Contaminants at the sediment-water interface: implications for environmental impact assessment and effects monitoring. Environ Sci Technol 47:5828-5834

Panchang V, Cheng G, Newell C (1997) Modeling hydrodynamics and aquaculture waste transport in coastal Maine. Estuaries 20:14-41

Partheniades E (1962) A study of erosion and deposition of cohesive soils in salt water. $\mathrm{PhD}$ thesis, University of California, Berkeley, CA

Reid GK, Liutkus M, Robinson SMC, Chopin TR and others (2009) A review of the biophysical properties of salmonid faeces: implications for aquaculture waste dispersal models and integrated multi-trophic aquaculture. Aquacult Res 40:257-273

Sanford LP (2008) Modeling a dynamically varying mixed sediment bed with erosion, deposition, bioturbation, consolidation, and armoring. Comput Geosci 34:1263-1283

Sanford LP, Maa JPY (2001) A unified erosion formulation for fine sediments. Mar Geol 179:9-23

Sanford LP, Panageotou W, Halka JP (1991) Tidal resuspension of sediments in northern Chesapeake Bay. Mar Geol 97:87-103

Shields A (1936) Application of the theory of similarity and turbulence research to bedload movement. Mitt Preuss Verssuchsanst Wasserbau Schiffbau 26:5-24

Soulsby R (1997) Dynamics of marine sands. A manual for practical applications. Thomas Telford Publishing, London

Stevens AW, Wheatcroft RA, Wiberg PL (2007) Sediment erodibility along the western Adriatic margin, Italy. Cont

Editorial responsibility: Catriona MacLeod,

Hobart, TAS, Australia
Shelf Res 27:400-416

> Stewart ARJ, Grant J (2002) Disaggregation rates of extruded salmon feed pellets: influence of physical and biological variables. Aquacult Res 33:799-810

Sutherland TF, Amos CL, Ridley C, Droppo IG, Petersen SA (2006) The settling behaviour and benthic transport of fish feed pellets under steady flows. Estuaries Coasts 29: 810-819

> Thomsen L, Gust G (2000) Sediment erosion thresholds and characteristics of resuspended aggregates on the western European continental margin. Deep-Sea Res I 47 : 1881-1897

Tolhurst TJ, Black KS, Shayler SA, Mather S, Black I, Baker K, Paterson DM (1999) Measuring the in situ erosion shear stress of intertidal sediments with the cohesive strength meter (CSM). Estuar Coast Shelf Sci 49:281-294

Tolhurst TJ, Black KS, Paterson DM, Mitchener HJ, Termatt GR, Shayler SA (2000) A comparison and measurement standardization of four in situ devices for measuring the erosion shear stress of intertidal sediments. Cont Shelf Res 20:1397-1418

> van Ledden M, van Kesteren WGM, Winterwerp JC (2004) A conceptual framework for the erosion behaviour of sand-mud mixtures. Cont Shelf Res 24:1-11

Wiberg PL, Smith DJ (1987) Calculations of the critical shear stress for motion of uniform and heterogeneous sediments. Water Resour Res 23:1471-1478

> Wiberg PL, Drake DE, Cacchione DA (1994) Sediment resuspension and bed armoring during high bottom stress events on the northern California inner continental shelf: measurements and predictions. Cont Shelf Res 14: 1191-1219

Wiberg PL, Law BA, Wheatcroft RA, Milligan TG, Hill PS (2013) Seasonal variations in erodibility and sediment transport potential in a mesotidal channel-flat complex, Willapa Bay, WA. Cont Shelf Res 60(Suppl):S185-S197

Winterwerp JC (1989) Flow induced erosion of cohesive beds. A literature survey. In: Cohesive sediments 25. WL/Delft Hydraulics and Rijkswaterstaat, Delft

Submitted: May 23, 2016; Accepted: August 17, 2016

Proofs received from author(s): October 11, 2016 